\title{
Bancroftiasis among the mumuye of Northeastern Nigeria: Parasitological and clinical studies in Northern Taraba State
}

\author{
Jacqueline A. Badaki ${ }^{1^{*}}$, Oladele B. Akogun ${ }^{2}$, Nobert B. Molta $^{3}$, Godwin Imandeh $^{3}$ \\ ${ }^{1}$ Department of Environmental Biology, Adekunle Ajasin University, Akungba-Akoko, Nigeria; \\ *Corresponding Author: jackie.badaki@gmail.com \\ ${ }^{2}$ Department of Biological Sciences, Federal University of Technology, Yola, Nigeria \\ ${ }^{3}$ Department of Biological Sciences, University of Jos, Jos, Nigeria
}

Received 15 November 2012; revised 16 December 2012; accepted 26 December 2012

\begin{abstract}
The study reports the prevalence of bancroftiasis in three Local Government Areas (LGAs) of Taraba State, Nigeria. Night blood samples collected from one thousand and thirty one individuals were stained with haematoxylin and examined microscopically for the presence of Wuchereria bancrofti. The overall prevalence of infection in the study area was high (21.2\%) but mean microfilaria densities were generally low. Statistically, prevalence rate differed significantly $\left(x_{\text {d.f. } 2}^{2}=10.498 ; P<0.05\right)$ between LGAs and despite the higher prevalence of microfilaraemia among males (22.7\%) (females: 19.7\%) there was no marked statistical difference $\chi_{\text {d.f.1 }}^{2}=$ 1.385; P > 0.05) between sexes. Infection also did not statistically differ between age groups $\left(x_{\text {d.f. }}^{2}=13.219 ; P>0.05\right)$ even though infection rate increased steadily with age and reaching a peak at the $40-49$ years age group. Lymphoedema was the commonest $(M=12.4 \%, F=19.2 \%)$ clinical manifestation of bancroftian morbidity encountered in the survey. Overall, the findings indicate that bancroftian filariasis is a public health problem in Taraba state and there is an urgent need to establish an elimination programme with a view of halting transmission in the area.
\end{abstract}

Keywords: Wuchereria Bancrofti; Morbidity; Microfilaraemia; Mumuye; Northeast Nigeria

\section{INTRODUCTION}

Globally, lymphatic filariasis (LF) affects about 120 million people in 73 countries with an estimated 512 million people at risk of the infection. 28 million people are reported to be infected in sub Saharan Africa alone [1]. High infection rates between $13 \%$ and $40 \%$ have been recorded in Kenya [2], Ghana [3-5] and Nigeria [6,7]. Filariasis have been reported in the Savanna [8] and rainforest-coastal zones of Nigeria $[9,10]$. Studies by Agi and Ebenezar, [11] have reported infection rate of $12.4 \%$, which is far above the WHO recommended $1 \%$ threshold necessary for initiation of mass treatment. Advanced forms of the disease result in chronic morbid manifestations such as hydrocoele (in males), lymphoedema of the breasts (in females) and limbs. Badaki and Akogun [12] have also previously reported severe morbidity due to Wuchereria bancrofti in Northeastern Nigeria. The infection can result in an altered lymphatic system and abnormal enlargement of body parts (limbs and genitals), causing severe pain and disability. Studies have described the psychological and socioeconomic burden of the disability on patients as excruciating with loss of income [13-15]. Unfortunately despite these indicators of filariasis in the country very little work has been documented on lymphatic filariasis in many parts of Nigeria. Studies on LF in Northeastern Nigeria are scanty and at the moment LF mapping showing a comprehensive nationwide distribution of LF is not available. There is presently no active elimination programme in the country; yet, people are constantly exposed to the vector mosquitoes. An urgent need to generate epidemiological data to assess the endemicity of the study area in order to justify the need for the establishment of mass treatment in the study area is paramount. The study also provides baseline data for the monitoring any future elimination programme.

\section{MATERIALS AND METHODS}

\subsection{Study Area}

The study was carried out in Lau, Yorro and Zing local 
Government areas (LGAs) of Taraba State where previous preliminary studies indicate cases of filarial elephantiasis [12]. The LGAs are largely rural, with Guinea Savannah vegetation and mean minimum and maximum temperatures of $24^{\circ} \mathrm{C}$ and $37^{\circ} \mathrm{C}$ respectively. The people live in dispersed compounds, protected by fences made of millet stalks but devoid of screens against mosquitoes. Rice paddies and broken clay pots that provide ideal breeding sites for the vector mosquitoes during the rainy season (Mid June to October) are common sights around compounds. The people are virtually unprotected from mosquito bites especially during the hot dry season (between February to Mid-June) when they sleep outdoors.

\subsection{Ethical Clearance}

Ethical clearance and informed consent was obtained from the University of Jos and Local health authorities before commencement of the study. Oral informed consent was given by participants and individuals were free to withdraw participation at any stage of the study. Written consent was not obtained because of the community's wide mistrust of signing official forms.

\subsection{Sampling Frame}

A two stage sampling was used for the study. First a list of all villages in the 3 Local Government areas (Zing, Yorro and Lau) was made and five communities were randomly selected from each LGA through balloting, giving a total of fifteen communities. In the second stage, every 5 th household in each selected community was sampled for the survey.

\subsection{Parasitological and Clinical Examinations}

In each selected house, oral informed consent was obtained from individuals aged above 18 years and from the parents of younger individuals. All the individuals who have lived in the community for at least one year were registered and their blood samples collected. $50 \mu \mathrm{l}$ blood was collected from each individual by finger prick between 22.00 and 02.00 hours using a heparinised capillary tube and used to make three thick smears on a clean slide [16]. The thick blood smears were air dried and stained with haematoxylin stain as described by WHO, [17] to quantify microfilaraemia. Microfilaraemia were identified based on specific morphological features, counted and recorded on pre-designed epidemiological data sheets.

Participants were also examined physically for clinical signs and symptoms of bancroftian filariasis using Dreyer et al., [18] assessment methods.

\subsection{Statistical Analysis}

Data was entered into SPSS for windows version 14 for statistical analysis. Differences in prevalence between LGAs, communities, sex and age were analysed by Chisquare. The microfilaria rate and mean microfilaria intensity in the various age groups was assessed by regression analysis.

\section{RESULTS}

A total of 1031 people were examined for microfilaraemia of Wuchereria bancrofti. The overall prevalence was $21.1 \%$ with the highest prevalence of infection (Table 1) recorded in Lau (26.4\%). Infection rates differed significantly between LGAs $\left(\chi_{\text {d.f. } 2}^{2}=10.498 ; \mathrm{P}<0.05\right)$ and prevalence of infection was slightly higher in males (22.7\%) than females (19.7\%) as shown on Table 2. However statistical analysis did not show any significant difference between the rates of infection in males and females $\left(\chi_{\text {d.f. } 1}^{2}=1.385 ; \mathrm{P}>0.05\right)$. Prevalence of infection steadily increased with age, reaching a peak amongst the middle aged (40 - 49 age groups) and followed by a sharp decrease in the older age groups (Table 2). The earliest age for acquisition of infection was four years old. Chi-square analysis showed an independent association between microfilaria rates in the various age groups and infection $\left(\chi_{\text {d.f.5 }}^{2}=1.696 ; \mathrm{P}<0.05\right)$. Even though there was great variability in individual MF load, there was no statistical difference between MF intensities between age groups $\left(\chi_{\text {d.f.25 }}^{2}=44.728 ; \mathrm{P}>0.05\right)$. However, the association between $\mathrm{mf}$-rate and $\mathrm{mf}$ intensity was observed to be significant $(r=0.015)$.

Table 3 summarises the clinical manifestations of bancroftian morbidity. Lymphoedema of the limbs $(\mathrm{M}=$ $12.4 \%, \mathrm{~F}=19.2 \%$ ) was the most commonly encountered clinical sign followed by hydrocoele $(6.1 \%)$ in males. Few cases of breast oedema (1.6\%) were also observed during the survey.

\section{DISCUSSION}

Information on the prevalence and distribution of any disease is necessary for determining its public health importance and the subsequent planning of any control programme. Reports on the distribution of filariasis in northern Savannah region of Nigeria are rather scanty. As a result, the true epidemiological situation of the disease is unknown in many communities, making it difficult to assess it public health importance.

The present study indicates that lymphatic filariasis is a health problem in Zing, Yorro and Lau local government areas (LGA) of Taraba State. The high prevalence of infection in all the three LGAs could be attributed to densities of mosquito populations and the humid climate 
Table 1. Prevalence of bancroftian infection in the study area.

\begin{tabular}{ccccc}
\hline LGA & Community & No. Examined & No. Infected & Proportion (\%) Infected \\
\hline Lau & Appawa & 135 & 40 & 29.6 \\
& Garin Mashi & 44 & 18 & 40.9 \\
& Garin Dogo & 60 & 14 & 23.3 \\
& Jimlari & 90 & 21 & 23.3 \\
& Kunini & 58 & 10 & 17.2 \\
Total & & 387 & 102 & 26.4 \\
Yorro & Dila & 145 & 26 & 17.9 \\
& Gadda & 111 & 23 & 20.7 \\
& Dadanvo & 34 & 9 & 25.0 \\
& Padanvo & 28 & 3 & 10.7 \\
& Mika & 63 & 5 & 7.9 \\
Total & & 65 & 17.1 \\
Zing & Dankoko & 76 & 15 & 19.7 \\
& Laapo & 74 & 12 & 16.2 \\
& Lapo & 36 & 15 & 41.7 \\
& Mazara & 57 & 9 & 15.8 \\
Total & Yobile & 20 & 1 & 5.0 \\
ALL & & 263 & 219 & 19.8 \\
\hline
\end{tabular}

Table 2. Prevalence and microfilarial intensities of Wuchereria bancrofti in the study area.

\begin{tabular}{|c|c|c|c|c|}
\hline Sex & No. Examined & No. Infected & Proportion (\%) Infected & Mean $\mathrm{mf} / 50 \mu 1$ \\
\hline Male & 537 & 122 & 22.7 & 10.4 \\
\hline Female & 494 & 97 & 19.6 & 9.1 \\
\hline Total & 1031 & 219 & 21.2 & 9.8 \\
\hline \multicolumn{5}{|c|}{ Age } \\
\hline$\leq 10$ & 166 & 6 & 3.6 & 5.9 \\
\hline $11-19$ & 250 & 47 & 18.8 & 8.5 \\
\hline $20-29$ & 203 & 49 & 24.1 & 11.6 \\
\hline $30-39$ & 165 & 36 & 21.8 & 11.8 \\
\hline $40-49$ & $128^{*}$ & 58 & 45.3 & 14.2 \\
\hline$\geq 50$ & 119 & 23 & 19.3 & 6.6 \\
\hline Total & 1031 & 219 & 21.2 & 9.8 \\
\hline
\end{tabular}

Table 3. Clinical signs of Bancroftian filariasis in the study sites.

\begin{tabular}{|c|c|c|c|c|c|}
\hline Age & No. Examined & Sex & Hydrocoele & Lymphoedema of the Limbs & Breast Odema \\
\hline \multirow{2}{*}{$<10$} & \multirow{2}{*}{166} & M 81 & 0 & 0 & 0 \\
\hline & & F 85 & 0 & 0 & 0 \\
\hline \multirow{2}{*}{$11-19$} & \multirow{2}{*}{250} & M 123 & $1(0.8)$ & 0 & 0 \\
\hline & & F 127 & 0 & $2(1.6)$ & 0 \\
\hline \multirow{2}{*}{$20-29$} & \multirow{2}{*}{203} & M 97 & $5(5.2)$ & $6(6.2)$ & 0 \\
\hline & & F 106 & 0 & $9(8.5)$ & $2(1.9)$ \\
\hline \multirow{2}{*}{$30-39$} & \multirow{2}{*}{165} & M 80 & $9(11.2)$ & $15(18.8)$ & 0 \\
\hline & & F 85 & 0 & $20(23.5)$ & $3(3.5)$ \\
\hline \multirow{2}{*}{$40-49$} & \multirow{2}{*}{128} & M 58 & $7(12.1)$ & $21(36.2)$ & 0 \\
\hline & & F 70 & 0 & $29(41.4)$ & $2(2.9)$ \\
\hline \multirow{2}{*}{$>50$} & \multirow{2}{*}{119} & M 55 & $7(12.7)$ & $17(30.9)$ & 0 \\
\hline & & F 64 & 0 & $23(35.9)$ & 0 \\
\hline \multirow{2}{*}{ Total } & \multirow{2}{*}{1031} & M 475 & $29(6.1)$ & $59(12.4)$ & 0 \\
\hline & & F 432 & 0 & $83(19.2)$ & $7(1.6)$ \\
\hline
\end{tabular}


which facilitates breeding of the vector mosquito. Human behavioural patterns probably play a role in transmission of the disease. Residents in the LGAs are very poor; living in mud huts thatched that lack basic protecttion from mosquito bites. The microfilaraemia prevalence are comparable with those conducted in other endemic areas of Africa [3,4]. Gender-specific activities could be responsible for the difference in the microfilaraemia rates in both sexes, though infection rates did not differ significantly. For instance the males stayed out late in the open and were often scantily dressed, thereby increasing chances of been bitten by the mosquito vectors.

Age patterns of microfilaraemia also followed those previously described from other endemic foci in Africa $[16,19]$. The very low MF prevalence recorded in young children (the 0 - 9 age group) could be due to the assumption that a large number of infective bites are required over a long period of time to establish a patent infection with microfilaraemia [20]. The decrease in prevalence in the older age group and the subsequent low $\mathrm{mf}$ intensities could be attributed to acquired immunological resistance to the presence of parasites over a long period of exposure to infection [21]. The argument that new infections require large number of infective bites could also be responsible for the low $\mathrm{mf}$ intensities in older age groups because after the death of old adult worms, acquisition of new infection would invariably be slowed down since exposure to infective bites for a long period of time could be a determining factor for establishment of new infections.

Lymphoedema of the limbs which is as a result of the failure of the lymphatic system to drain away lymphatic fluid from the tissues was the commonest morbid manifestation in the study area. Females appeared to be more predisposed to the lymphoedema than males than because of perhaps because of hormonal factors; however this needs to be further investigated. The proportion of individuals observed to have LF related hydrocoele was rather low when compared to similar studies in other endemic parts of Africa. Individuals with Hydrocoele in the study area are often teased and perhaps affected individuals avoided participating in the survey in order to avoid being teased by the wider community.

In conclusion, the findings show that lymphatic filariasis is a problem in Northern parts of Taraba State and there is urgent need to establish an elimination programme with a view of halting transmission in the area.

\section{ACKNOWLEDGEMENTS}

We are grateful to the Taraba State Ministry of Health and the community leaders in Zing, Yorro and Lau Local Government areas for granting permission to carry out the study under the technical support of the Common Heritage Foundation, Nigeria.

\section{REFERENCES}

[1] Micheal, E., Bundy, D.A.P. and Grenfell, B.T. (1996) Reassessing the global prevalence and distribution of lymphatic filariasis. Parasitology Today, 112, 409-428.

[2] Estambale B.B.A., Simonsen, P.E., Knight, R. and Bwayo, J.J. (1994) Bancroftian Filariasis in Kwale district of Kenya. I. Clinical and Parasitological survey in an endemic community. Annals of Tropical Medicine and Hygiene, 88, 145-151

[3] Dzodzomenyo, M., Dunyo, S.K. Ahorlu, C.K., Coker, W.Z., Appawa, M.A., Pedersen, E.M. and Simonsen, P.E. (1999) Bancroftian filariasis in an irrigation project community in southern Ghana. Tropical Medicine and International Health, 4, 13-18. doi:10.1046/j.1365-3156.1999.00354.x

[4] Gyapong, J.O., Magnussen, P. and Binka, F.N. (1994) Parasitological and clinical aspects of Bancroftian filariasis in Kassena-Nankana District, Upper East Region Ghana. Transactions of the Royal Society of Tropical Medicine and Hygiene, 88, 555-557. doi:10.1016/0035-9203(94)90160-0

[5] Gyapong, J.O. (1998) The relationship between infection and disease in Wuchereria bancrofti infection in Ghana. Transactions of the Royal Society of Tropical Medicine and Hygiene, 92, 390-392. doi:10.1016/S0035-9203(98)91058-6

[6] Lindsay, S.W. and Thomas, C.J. (2000) Mapping and estimating the population at risk for lymphatic filariasis in Africa. Transactions of the Royal Society of Tropical Medicine and Hygiene, 94, 37-45. doi:10.1016/S0035-9203(00)90431-0

[7] Hopkins, D.R., Eigege, A., Miri, E.S., Gontor, I., Ogah, G., Umaru, J., Gwomkudu, C.C., Mathai, W., Jinadu, M. Amadiegwu, S.O., Oyenekan, K., Korve, K. and Richards Jr., F.O. (2002) Lymphatic filariasis elimination and schistosomiasis control in combination with onchocerciasis control in Nigeria. American Journal of Tropical Medicine and Hygiene, 67, 266-272.

[8] Akafyi, D., Akogun, O.B. and Chessed, G. (2003) Prevalence and Intensity of lymphatic filariasis in two communities in Zing Local Government Area, Taraba state, Nigeria. Journal of Tropical Biosciences, 3, 55-58

[9] Anosike, J.C., Nwoke, B.E.B, Ajayi, E. Onwuliri, C.O.E., Okoro, O.U., Oku, E.E., Asor, J.E., O.U. Amajuoyi, Ikpeama, C.A., Ogbusu, F.I. and Meribe, C.O. (2005) Lymphatic filariasis among the ezza People of Ebonyi State, Eastern Nigeria. Annals of Agriculture and Environmental Medicine, 12, 181-186.

[10] Ajero, C.M.U., Nwoke, B.E.B., Okolie, N.J.C., Nwanjo, H.U., Oze, G., Okafor, M.C., Nwosu, D. Anyaehie, B. and Uloneme, G.C. (2007) Bancroftian filariasis in the Niger Delta Area of Eastern Nigeria. Research Journal of Medical Sciences, 1, 113-117.

[11] Agi, P.I. and Ebenezar, A. (2009) Observations on filarial Infection in Amassoma Community in Niger Delta, Nigeria. Journal of Applied Science and Environmental Management, 13, 15-19.

[12] Badaki, J.A. and Akogun, O.B. (2002) Severe morbidity 
due to lymphatic filariasis in Taraba state, Nigeria. Nigerian Journal of Parasitology, 22, 105-112.

[13] Kumari, A.K., Harichandrakumar, K.T., Das, L.K. and Krishnamoorthy, K. (2005) Physical and psychosocial burden due to lymphatic filariasis as perceived by patients and medical experts. Tropical Medicine and International Health, 10, 567-573. doi:10.1111/j.1365-3156.2005.01426.x

[14] Babu, B.V., Mishra, S., Nayak, A.N. (2009) Marriage, sex, and hydrocele: An ethnographic study on the effect of filarial hydrocele on conjugal life and marriageability from Orissa, India. PLOS Neglected Tropical Diseases, 3, e414. doi:10.1371/journal.pntd.0000414

[15] Person, B., Bartholomew, L.K., Gyapong, M., Addiss, D.G. and van den Borne, B. (2009) Health-related stigma among women with lymphatic filariasis from the Dominican Republic and Ghana. Social Science \& Medicine, 68, 30-38. doi:10.1016/j.socscimed.2008.09.040

[16] Kimura, E., Penaia, L. and Spears, G.F.S. (1985) Epidemiology of sub-periodic bancroftian filariasis in Samoa 8 years after control by mass treatment with diethylcarbamazine. Bulletin of the World Health Organisation, 63,
869-880.

[17] WHO (1991) Basic laboratory methods in medical parasitology. World Health Organisation, Geneva, 38-45

[18] Dreyer, G., Addiss, D, Dreyer, P. and Noroes, J. (2002) Assessment of chronic lymphoedema. Basic Lymphoedema Management, Hollis Publishing Company, Hollis, 111.

[19] Simonsen, P.E., Meyrowitsch, T.W., Makunde, W. H. and Magnussen, P. (1995) Bancroftian filariasis: The pattern of microfilaraemia and clinical manifestations in three endemic communities in North-Eastern Tanzania. Acta Tropica, 60, 179-180. doi:10.1016/0001-706X(95)00126-Y

[20] Day, K.P., Gregory, W.F. and Maize's, R.M. (1991) Age specific acquisition of immunity to infective larvae in a bancroftian filariasis endemic area of Papua New Guinea. Parasite Immunology, 13, 277-290. doi:10.1111/j.1365-3024.1991.tb00282.x

[21] Southgate, B.A. (1992) Intensity of transmission and development of microfilaraemia and disease: Their relationship to lymphatic filariasis. Journal Tropical Medicine and Hygiene, 95, 1-12. 